\title{
Approaches to neuromodulation for schizophrenia
}

\author{
Judith M Gault, ${ }^{1,2}$ Rachel Davis, ${ }^{2}$ Nicola G Cascella, ${ }^{3}$ Elyn R Saks, ${ }^{4}$ \\ Iluminada Corripio-Collado, ${ }^{5,6}$ William S Anderson, ${ }^{7}$ Ann Olincy, ${ }^{2}$ John A Thompson, ${ }^{1}$ \\ Edith Pomarol-Clotet, ${ }^{8}$ Akira Sawa, ${ }^{3}$ Zafiris J Daskalakis, ${ }^{9}$ Nir Lipsman, ${ }^{10}$ \\ Aviva Abosch ${ }^{1,11}$
}

For numbered affiliations see end of article.

\section{Correspondence to} Dr Judith M Gault, Department of Neurosurgery, University of Colorado Denver Anschutz Medical Campus, Aurora, CO 80045-0508, USA; judith. gault@ucdenver.edu

Received 27 July 2017 Revised 9 October 2017 Accepted 29 October 2017 Published Online First 14 December 2017

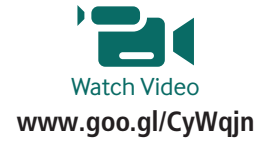

Check for updates

To cite: Gault JM, Davis $\mathrm{R}$ Cascella NG, et al. J Neurol Neurosurg Psychiatry 2018:89:777-787.

\section{ABSTRACT}

Based on the success of deep brain stimulation (DBS) for treating movement disorders, there is growing interest in using DBS to treat schizophrenia (SZ). We review the unmet needs of patients with $S Z$ and the scientific rationale behind the DBS targets proposed in the literature in order to guide future development of DBS to treat this vulnerable patient population. SZ remains a devastating disorder despite treatment. Relapse, untreated psychosis, intolerable side effects and the lack of effective treatment for negative and cognitive symptoms contribute to poor outcome. Novel therapeutic interventions are needed to treat SZ and DBS is emerging as a potential intervention. Convergent genetic, pharmacological and neuroimaging evidence implicating neuropathology associated with psychosis is consistent with $\mathrm{SZ}$ being a circuit disorder amenable to striatal modulation with DBS. Many of the DBS targets proposed in the literature may modulate striatal dysregulation. Additional targets are considered for treating tardive dyskinesia and negative and cognitive symptoms. A need is identified for the concurrent development of neurophysiological biomarkers relevant to SZ pathology in order to inform DBS targeting. Finally, we discuss the current clinical trials of DBS for $S Z$, and their ethical considerations. We conclude that patients with severe symptoms despite treatment must have the capacity to consent for a DBS clinical trial in which risks can be estimated, but benefit is not known. In addition, psychiatric populations should have access to the potential benefits of neurosurgical advances.

\section{CURRENT STATE OF TREATMENT FOR SCHIZOPHRENIA}

- Schizophrenia (SZ) remains a devastating disorder despite antipsychotic, psychological and social treatments. ${ }^{1}$

- Only 10\%-20\% find competitive employment. ${ }^{1}$

- Relapse, antipsychotic inefficacy, intolerable side effects and lack of treatment for negative and cognitive symptoms contribute to poor outcome. ${ }^{1-5}$

- Novel therapies need to be explored and deep brain stimulation (DBS) is emerging as a potential intervention. ${ }^{5}$

SZ affects about one in a hundred. Psychosis, the hallmark symptom of SZ, includes hallucinations and/or delusions that render patients unable to discern aspects of reality. In addition, patients may experience negative and cognitive symptoms that significantly impair independent functioning. Negative symptoms, such as social withdrawal and general apathy, are prominent in $20 \%-40 \%$ of patients with SZ. ${ }^{5}$ Cognitive impairment affecting all domains of neuropsychological function is a common feature of the disorder. Novel pharmacological, psychological, social and neurosurgical treatments are being developed due to the minimal effect that currently available treatments have on negative and cognitive symptoms. ${ }^{5}$

With the availability of antipsychotics, $60 \%$ of patients with SZ improve long term though the majority remain disabled. ${ }^{1}$ Most antipsychotics have similar efficacy with the exception of clozapine, a notably more effective antipsychotic used in treatment-resistant patients. ${ }^{6}$ Relapse is a critical barrier to optimal recovery and $61 \%-82 \%$ of patients with SZ experience a relapsing and remitting disease course. ${ }^{17}$ Relapse contributes to alienation, accidental injury, death and possibly to progressive brain pathology. ${ }^{4}$ Despite treatment compliance, relapse occurs in 19\%-30\% of patients each year. ${ }^{2}$ However, relapse is primarily due to antipsychotic non-adherence, often the result of medication inefficacy and intolerable side effects. ${ }^{3}$

Most patients taking antipsychotics experience one or more side effects. These side effects include: extrapyramidal symptoms related to movement (34\%-58\%), hyperprolactinaemia (31\%-39\%), akathisia (7\%-35\%), sedation (47\%), fatigue $(60 \%)$ and sexual dysfunction $(30 \%-80 \%) .{ }^{3}$ Other life-threatening side effects include agranulocytosis, impaired glucose metabolism, myocarditis, neuroleptic malignant syndrome, seizures and significant weight gain. ${ }^{3}$ In summary, novel therapeutic interventions for the treatment of SZ are needed for the 19\%-25\% of individuals with poor outcome, 19\%-30\% of individuals who consistently relapse and $15 \%$ of individuals experiencing intolerable or life-threatening antipsychotic side effects.

Precedent for DBS treatment of symptoms of SZ has been demonstrated with the success of DBS for treatment-resistant Parkinson's disease (PD), essential tremor (ET) and dystonia, and is being investigated for psychiatric illnesses like major depression and obsessive-compulsive disorder (OCD). ${ }^{8-11}$ As for PD, ET, dystonia, major depression and OCD, we present evidence that $\mathrm{SZ}$ is a circuit disorder and therefore might be amenable to neuromodulation with DBS to treat disease symptoms. 
Neuropsychiatry

\begin{tabular}{|c|c|c|c|c|c|}
\hline Reference & Ctrl & SZ & \multicolumn{2}{|l|}{ Method } & Brain region results/effect size \\
\hline Kambeitz et $\mathrm{al}^{16}$ & 265 & 278 & \multicolumn{2}{|l|}{$\mathrm{D}_{2}$-like receptor availability } & $\begin{array}{l}\text { No change in } \mathrm{D}_{2} \text { receptors in extrastriatal temporal cortex, } \\
\text { thalamus or substantia nigra }\end{array}$ \\
\hline Yilmaz et al ${ }^{19}$ & - & 206 & \multicolumn{2}{|l|}{ PET/SPECT $D_{2}$ occupancy } & $\begin{array}{l}\text { Antipsychotics at } 60 \%-80 \% \text { occupancy in the striatum are } \\
\text { correlated (1.35) with improvement of psychotic symptoms. }\end{array}$ \\
\hline Howes et $a l^{21}$ & 231 & 251 & \multicolumn{2}{|l|}{ PET PDA (L-DOPA uptake) } & $\begin{array}{l}\text { Presynaptic dopamine is elevated in the striatum (large effect } \\
\text { size }=0.79 \text { ). }\end{array}$ \\
\hline Minzenberg et $a P^{4}$ & 623 & 594 & \multicolumn{2}{|l|}{ ALE fMRI executive function } & $\begin{array}{l}\text { Decreased activation in DLPFC, VLPFC, ACC, medial dorsal } \\
\text { thalamus }\end{array}$ \\
\hline Bernard et $a l^{13}$ & 707 & 583 & \multicolumn{2}{|c|}{$\begin{array}{l}\text { ALE during emotion, executive function, language, motor, } \\
\text { reward and working memory tasks }\end{array}$} & $\begin{array}{l}46 \% \text { decreased activation in the basal ganglia during tasks } \\
\text { requiring coordination with the frontal cortex }\end{array}$ \\
\hline Kühn and Gallinat ${ }^{18}$ & 282 & 285 & \multicolumn{2}{|c|}{$\begin{array}{l}95 \text { of } 285 \text { off antipsychotics } \\
\text { ALE resting state fMRI }\end{array}$} & $\begin{array}{l}\text { Hypoactivation of the left hippocampus in the default mode } \\
\text { network }\end{array}$ \\
\hline Radua et $a^{15}$ & $\begin{array}{l}\text { 1) } 439 \\
\text { 2) } 175 \\
\text { 3) } 159\end{array}$ & $\begin{array}{l}\text { 1) } 478 \\
\text { 2) } 183 \\
\text { 3) } 155\end{array}$ & \multicolumn{2}{|c|}{$\begin{array}{l}\text { fMRI of monetary reward; correlation with positive and } \\
\text { negative symptoms: } \\
\text { 1) anticipation } \\
\text { 2) feedback } \\
\text { 3) prediction error }\end{array}$} & $\begin{array}{l}\text { Hypoactivation of ventral striatum during feedback } \\
(\mathrm{r}=-0.56 \text { to }-0.57) \text { and reward anticipation }(\mathrm{r}=-0.5 \text { to }-0.7) \\
\text { that was correlated with negative symptoms }(r=-0.41)\end{array}$ \\
\hline Adriano et $a P^{22}$ & $\begin{array}{l}\text { 1) } 2130 \\
\text { 2) } 562 \\
\text { 3) } 896\end{array}$ & $\begin{array}{l}\text { 1) } 1617 \\
\text { 2) } 388 \\
\text { 3) } 739\end{array}$ & \multicolumn{2}{|c|}{$\begin{array}{l}\text { MRI volumetric analysis } \\
\text { 1) All patients mixed } \\
\text { 2) First-episode SZ } \\
\text { 3) Chronic SZ }\end{array}$} & Hippocampal reduction effect size $(-0.48$ to -0.65$)$ \\
\hline $\begin{array}{l}\text { Ellison-Wright and } \\
\text { Bullmore }^{26}\end{array}$ & 383 & 407 & \multicolumn{2}{|l|}{ DTI fractional anisotropy connectivity } & $\begin{array}{l}\text { Reduction in left deep white matter tract connectivity in } \\
\text { frontal (SGCWM DBS target) and temporal lobes }\end{array}$ \\
\hline Sayo et al ${ }^{20}$ & $72^{*}$ & $72^{*}$ & \multicolumn{2}{|c|}{ Ventricular-to-brain ratio SZ vs controls } & Increased 0.3-fold in lateral ventricles \\
\hline Merritt et al ${ }^{14}$ & 1451 & 1686 & \multicolumn{2}{|c|}{$\begin{array}{l}\text { Glutamate proton magnetic resonance spectroscopy } \\
\text { To measure glutamate and metabolites }\end{array}$} & $\begin{array}{l}\text { Increased glutamate and metabolites in basal ganglia, } \\
\text { thalamus and hippocampus (effect size } 0.32-0.63 \text { ) }\end{array}$ \\
\hline Kegeles et a $\left.\right|^{23}$ & 18 & 18 & \multicolumn{2}{|c|}{ PET synaptic DA } & $\begin{array}{l}\text { Increased presynaptic DA } 0.67 \text {-fold in associative striatum. No } \\
\text { change in ventral or sensorimotor striatum }\end{array}$ \\
\hline Eisenberg et $a^{12}$ & & 30 & \multicolumn{2}{|c|}{$\begin{array}{l}\text { 3-week atypical antipsychotics effects: } \\
\text { 1) PET presynaptic DA } \\
\text { 2) PET rCBF } \\
\text { 3) executive function subscale PANSS }\end{array}$} & $\begin{array}{l}\text { Antipsychotic-induced increase in both presynaptic DA, and } \\
\text { rCBF in VS and decreased executive function in VS }\end{array}$ \\
\hline Lahti et $a l^{25}$ & & 29 & \multicolumn{2}{|c|}{$\begin{array}{l}\text { PET rCBF responder ( } n=13 \text { ) vs poor responder }(n=16) \text { to } \\
\text { antipsychotics }\end{array}$} & Increased rCBF in VS in responders \\
\hline Schobel et al $1^{17}$ & & 19 & \multicolumn{2}{|c|}{$\begin{array}{l}\text { Prodromal ( } 9 \text { converted to psychotic vs } 10 \text { who did not) } \\
\text { 1. CBV ( } 2 \text { time points) } \\
\text { 2. volume ( } 2 \text { time points) }\end{array}$} & $\begin{array}{l}\text { Decreased cerebral blood volume in the CA1 and subiculum } \\
\text { and decreased volume in hippocampus }\end{array}$ \\
\hline \multicolumn{6}{|c|}{$\begin{array}{l}\text { Bold denotes meta-analysis. } \\
\text { *72 studies included with patients and control subjects. } \\
\text { ACC, anterior cingulate cortex; ALE, activation likelihood estimate; AS, associative striatum; CA1, cornu ammonis 1; CBV, cerebral blood volume; Ctrl, controls; D2, dopamine } \\
\mathrm{D}_{2} \text {-like receptor; DA, dopamine; DBS, deep brain stimulation; DLPFC, dorsolateral prefrontal cortex; DTI, diffusion tensor imaging; fMRI, functional MRI; L-DOPA, L-3,4- } \\
\text { dihydroxyphenylalanine; PANSS, Positive and Negative Syndrome Scale; PDA, presynaptic dopamine; PET, positron emission tomography; rCBF, regional cerebral blood } \\
\text { flow; SGCWM, subgenual cingulate white matter; SN, substantia nigra; SPECT, single-photon emission CT; SZ, schizophrenia; T, thalamus; TC, temporal cortex; TL, temporal lobe; } \\
\text { VLPFC, ventrolateral prefrontal cortex; VS, ventral striatum. }\end{array}$} \\
\hline \multicolumn{4}{|c|}{$\begin{array}{l}\text { METHODS } \\
\text { A systematic review of the literature was performed using } \\
\text { the search terms 'schizophrenia' and 'meta' and 'imaging' } \\
\text { in PubMed in May } 2017 \text {. Of the resulting studies } 11 \\
\text { non-redundant studies were included in table } 1 \text { (in bold) } \\
\text { in order to summarise robust findings implicating brain } \\
\text { regions relevant to SZ. }{ }^{12-26} \text { A second systematic review } \\
\text { was performed in PubMed using the search terms 'schizo- } \\
\text { phrenia' and 'deep brain stimulation' to identify DBS } \\
\text { targets implicated in SZ (table } 2 \text {, figure } 1 \text { ). }{ }^{5} 91016172527-42 \\
\text { References from these manuscripts were also considered } \\
\text { and each DBS clinical trial site identified references that } \\
\text { supported the scientific rationale for their trial (figure } 1 \text {, } \\
\text { table } 2 \text { ). } 5 \text { } 1016172527-42 \text { Additional manuscripts related } \\
\text { to DBS mechanisms, SZ treatment, potential SZ biomarkers, } \\
\text { ethics and mechanistic models of circuitry involved in SZ } \\
\text { were included (figure } 1 \text {, tables } 1 \text { and } 2 \text { ). }{ }^{5} 91012-36\end{array}$} & \multicolumn{2}{|c|}{$\begin{array}{l}\text { Psychosis and the striatum } \\
\text { The dopamine } \mathrm{D}_{2} \text { receptor gene (DRD2) is genetically asso- } \\
\text { ciated with } \mathrm{SZ}_{4}{ }^{2} \\
\text { Antipsychotic potencies are associated with affinity for } \\
\text { dopamine } \mathrm{D}_{2} \text {-like receptors }\left(\mathrm{D}_{2}\right) .^{44} \\
\text { Striatum includes the highest concentration of } \mathrm{D}_{2}{ }^{44} \\
\text { Ventral striatum (VS) and associative striatum (AS) are } \\
\text { possible DBS targets with potential to normalise dopamin- } \\
\text { ergic tone in the striatum. } \\
\text { Convergent and robust evidence implicates aberrancy in dopa- } \\
\text { minergic circuitry causing psychosis (tables } 1 \text { and } 2 \text {; figure } 1 \text { ). }{ }^{12-26} \\
\text { Genetic loci involved in SZ genesis were recently identified in } \\
\text { a large genome-wide association study. }{ }^{43} \text { This study strength- } \\
\text { ened several previous findings, including the largest association } \\
\text { with the major histocompatibility complex locus on chromo- } \\
\text { some } 6 \text {, involvement of an N-methyl-D-aspartate (NMDA) } \\
\text { receptor (GRIN2A) with other glutamatergic genes, and the }\end{array}$} \\
\hline
\end{tabular}


Table 2 Possible DBS targets and effects on schizophrenia symptoms

\begin{tabular}{|c|c|c|c|c|c|}
\hline \multirow{2}{*}{$\begin{array}{l}\text { DBS } \\
\text { target }\end{array}$} & \multirow[b]{2}{*}{ Subterritory } & \multirow[b]{2}{*}{ Models of aberrant circuitry } & \multicolumn{3}{|l|}{ Hypothetical effects of DBS } \\
\hline & & & Positive & Negative & Cognitive \\
\hline VS & NAC & $\begin{array}{l}\text { 1) Hippocampal disinhibition of } \\
\text { striatum leads to } \uparrow D A \text { in VS. }{ }^{17 *} \\
\text { 2) } \uparrow \text { Striatal DA inhibits GLU } \\
\text { signalling in VS. } .^{25} \\
\text { 3) } \uparrow \text { Striatal DA, but } \downarrow D A \text { to } \\
\text { reward circuit within VS (NAc) } \\
\text { and frontal cortex }{ }^{27}\end{array}$ & $\begin{array}{l}\text { 1) Block } \uparrow \text { DA signalling in VS } \\
\text { normalises striatal DA. }{ }^{28} 293135 \\
\text { 2) Restore GLU signalling in VS. }{ }^{25} \\
\text { 3) May } \uparrow D A \text { overall in striatum }{ }^{9}\end{array}$ & $\begin{array}{l}\text { Investigational target for } \\
\text { depression }{ }^{5282931} \\
\text { 1) Block } \uparrow \mathrm{DA} \text { signalling in VS* } \\
\text { restoring reward response } \\
\text { 2) Restore GLU signalling in VS. } \\
\text { 3) } \uparrow \mathrm{DA} \text { signalling needed for } \\
\text { reward pathway }\end{array}$ & 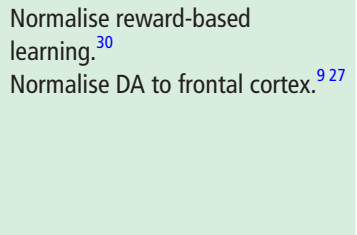 \\
\hline mPFC & SGCWM & $\begin{array}{l}\text { 4) Default network } \\
\text { deactivation failure, possible } \\
\text { overactivation } 3344\end{array}$ & & $\begin{array}{l}\text { Investigational target for } \\
\text { depression. Modulation of the } \\
\text { default network }\end{array}$ & \\
\hline $\mathrm{SNr}$ & Below STN & 5) MD inhibition ${ }^{36-42}$ & MD disinhibition & & MD disinhibition \\
\hline VTA & Ascending & $\begin{array}{l}\text { 3) } \downarrow D A \text { in NAc and PFC } \\
\text { contributes to cognitive } \\
\text { deficits. }{ }^{1627}\end{array}$ & $\begin{array}{l}\text { Normalising striatal dopaminergic } \\
\text { tone through } \uparrow \text { DA NAc and } \\
\text { feedforward DA spiral regulation } \\
\text { of } S N \text { and } \mathrm{AS}^{35} \text { or } \uparrow \text { striatal DA may } \\
\text { contribute to psychosis. }\end{array}$ & $\begin{array}{l}\text { TDA NAc effects on reward/ } \\
\text { motivation pathways }{ }^{577}\end{array}$ & TDA in PFC \\
\hline AS & $\begin{array}{l}\text { Region connecting to } \\
\text { DLPFC }\end{array}$ & $\begin{array}{l}\text { 6) Cognitive deficits related } \\
\text { to dysregulation of circuitry to } \\
\text { prefrontal cortex }{ }^{1648}\end{array}$ & $\begin{array}{l}\text { Possible modulation DA signalling } \\
\text { involved in psychosis }{ }^{48}\end{array}$ & & Modulation DA signalling to $\mathrm{PFC}^{48}$ \\
\hline MSN & & $\begin{array}{l}\text { 1) Excess extracellular GLU in } \\
\text { hippocampus }{ }^{17}\end{array}$ & $\begin{array}{l}\text { Prevent hippocampal disinhibition } \\
\text { of striatum, normalise striatal } \\
\text { DA. }^{30}\end{array}$ & $\begin{array}{l}\text { Normalise reward/motivation } \\
\text { pathway DA. }{ }^{5}\end{array}$ & Normalise DA signalling to PFC. \\
\hline GPi & Posteroventrolateral $^{10}$ & $\begin{array}{l}\text { 7) Antidyskinetic treatment of } \\
\text { tardive dyskinesia }^{10}\end{array}$ & & & \\
\hline H & CA1 & 1) Striatal disinhibition ${ }^{1732}$ & Normalise striatal DA. $^{32}$ & $\begin{array}{l}\text { Normalise reward/motivation } \\
\text { pathway DA. }{ }^{5}\end{array}$ & Normalise DA signalling to PFC. ${ }^{32}$ \\
\hline
\end{tabular}

\begin{abstract}
${ }^{*}$ High levels of dopamine make NAc cells less responsive to reward-based dopamine changes leading to negative symptoms in some patients with schizophrenia (SZ) (this is also consistent with patients being more susceptible to cigarette addiction where addition occurs in subjects with smaller responses requiring more of the addictive substance). AS, associative striatum; CA1, cornu ammonis 1; DA, dopamine; DBS, deep brain stimulation; DLPFC, dorsolateral prefrontal cortex; GLU, glutamate; GPi, globus pallidus internal; H, hippocampus; MD, medial dorsal; mPFC, medial prefrontal cortex; MSN, medial septal nucleus; NAc, nucleus accumbens; PFC, prefrontal cortex; SGCWM, subgenual cingulate white matter; SN, substantia nigra; SNr, substantia nigra pars reticulata; STN, subthalamic nucleus; VS, ventral striatum; VTA, ventral tegmental area.
\end{abstract}

DRD2 gene-the $\mathrm{D}_{2}$ receptor is an essential target of antipsychotics. ${ }^{43}$ Discovered in 1950 , antipsychotics are proven effective at treating psychosis and their mechanism of action provides insight into aspects of the molecular underpinnings of psychosis. ${ }^{6}$ The finding that mean doses of different antipsychotics were correlated with their binding affinity for $\mathrm{D}_{2}$ demonstrated how essential $\mathrm{D}_{2}$ binding is to antipsychotic action. ${ }^{44}$

The challenge has been to identify brain regions bearing $\mathrm{D}_{2}$ that specifically contribute to the antipsychotic effect. Although further investigation into dopaminergic changes in extrastriatal regions is warranted, $\mathrm{D}_{2}$ availability in temporal cortex, thalamus and substantia nigra was not significantly altered in patients with SZ (table 1). Relative to extrastriatal areas, $\mathrm{D}_{2}$ density is 5-20-fold higher throughout the striatum. In striatum, postsynaptic $\mathrm{D}_{2}$ has primarily been identified on a subpopulation of medium spiny neurons (the most prominent striatal cell type). $\mathrm{D}_{2}$ activation suppresses depolarisation and the molecular pathway common to antipsychotics occurs through recruitment of $\beta$-arrestin 2, a scaffolding molecule that organises a signalling cascade involving protein phosphatase $2 \mathrm{~A}, \mathrm{AKT} 1$ and GSK3 $\beta$, to regulate $\beta$-catenin-mediated signalling. ${ }^{45}$

Neuroimaging studies using positron emission tomography (PET) or single-photon emission CT have quantitated displacement of radiolabeled neurochemicals relevant to the brain dopamine transporters, $D_{2}$ availability, $D_{2}$ occupancy, dopamine synthesis and amphetamine-induced dopamine release. These studies indicate that $\mathrm{D}_{2}$ receptor occupancy in striatum is positively related to clinical improvement, and the therapeutic window for antipsychotics with moderate to high affinity for $\mathrm{D}_{2}$ occurs at a receptor occupancy level of $60 \%-80 \%$ in the striatum (table 1). ${ }^{19} \mathrm{D}_{2}$ receptor numbers show a small elevation in patients with SZ. ${ }^{21^{2}}$ However, the major finding in first-episode, medication-naïve patients, and in patients receiving antipsychotic treatment, was an elevation of presynaptic dopamine in the striatum measured in multiple ways-including radiolabeled L-3,4-dihydroxyphenylalanine uptake, amphetamine-induced dopamine release and basal levels of synaptic dopamine (table 1$).{ }^{21}$ Finally, striatal dysfunction may be distinct in treatment-resistant patients with SZ. ${ }^{46} 47$ Fortunately, DBS programming individually optimises therapy and may be able to compensate for some variation between patients. Still, DBS response is anticipated to vary based on target and patient selection.

The striatum serves as the primary input structure to the basal ganglia (BG), and can be divided into VS, AS and sensorimotor striatum (SMS), based on cortico-striato-thalamic topography of multiple parallel circuits (figure 2). ${ }^{48}$ Both VS and AS have been indirectly implicated in generating the psychotic symptoms. Four studies have identified higher dopamine activity in the AS relative to SMS in patients with SZ (table 1). ${ }^{23} 48$ Two PET studies identified the VS as having the most significant antipsychotic-induced change in regional cerebral blood flow ( $\mathrm{rCBF}$ ) within the striatum. Still, other areas of the striatum were also significantly changed. Results relating changes in $\mathrm{rCBF}$ in VS to improvement in symptoms were less consistent (table 1). ${ }^{12}{ }^{25}$ However, one investigation went on to demonstrate that this $\mathrm{rCBF}$ change in VS was associated with presynaptic dopamine synthesis capacity in the VS. ${ }^{12}$ Clearly striatal modulation is warranted and regulation of striatal dopamine has been described as an ascending, feedforward spiral of information flow (figure 2). ${ }^{35}$ Therefore, 

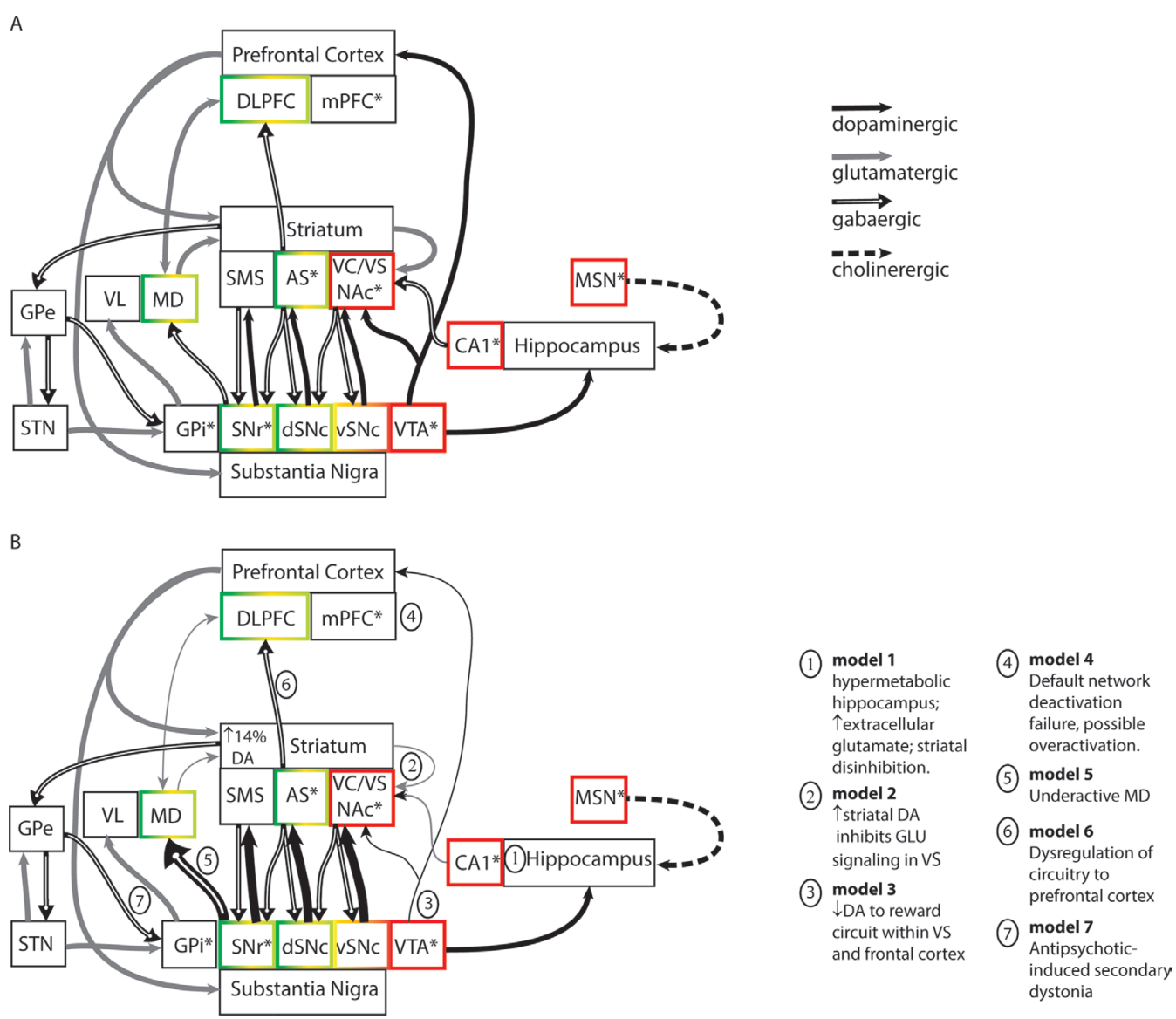

Figure 1 Striatal circuitry within the basal ganglia-thalamocortical circuit. *Potential deep brain stimulation (DBS) targets to treat schizophrenia (SZ) from table 2 and figure 3; A. Normal circuitry. B. Effects of aberrancies implicated in schizophrenia circuitry. grey arrows=glutamatergic; black arrows=dopaminergic; black striped=GABAergic; black dashed=cholinergic; ACC, anterior cingulate cortex; $A$, associative striatum; DG, dentate gyrus; DLPFC, dorsolateral prefrontal cortex; dSNc, dorsal tier SNc; GPe/GPi, globus pallidus external/internal; MD, medial dorsal; mPFC, medial prefrontal cortex; MSN, medial septal nucleus; NAc, nucleus accumbens; SGCWM, subgenual cingulate white matter; SMS, sensorimotor striatum; SNc/r, substantia nigra pars compacta/pars reticulata; STN, subthalamic nucleus; VCNS, ventral capsule/ventral striatum; VIM, ventral intermediate nucleus; vSNc, ventral tier SN pars compacta; VTA, ventral tegmental area.

modulation of VS may influence AS and SMS dopamine levels (figure 1, table 2). $591016172527-42$

\section{Neuromodulation of frontal and temporal lobe circuitry}

- Striatum in conjunction with frontal lobe circuitry contributes to negative and cognitive symptoms.

- DBS of hippocampus and medial septal nucleus (MSN) may modulate striatal circuitry.

In addition to being implicated in psychosis, striatal dysfunction may contribute to negative and cognitive symptoms of SZ through circuitry involving the frontal and temporal lobes (table 1). ${ }^{12-26}$ Functional neuroimaging studies involving tasks assessing emotion, executive function, language, motor, reward and working memory demonstrated an overall decreased activation in BG and thalamus when these brain areas were required to coordinate with frontal cortex (table 1). ${ }^{13} 24$ Targeting AS with DBS may treat cognitive deficits in SZ due to its connectivity to dorsolateral prefrontal cortex (DLPFC). DLPFC has been targeted with repetitive transcranial magnetic stimulation (rTMS) to treat cognitive deficits with positive effects on working memory in 74 patients with SZ with active rTMS compared with 78 sham rTMS $(\mathrm{g}=0.507, \mathrm{P}<0.01){ }^{49}$

While VS is a primary candidate for targeting psychosis, it is also a candidate for targeting negative symptoms of SZ due to its role in the reward circuitry involving ventral tegmental area (VTA), nucleus accumbens (NAc) and prefrontal cortex. ${ }^{15}$ Striatal activation, assessed with functional MRI (fMRI), occurs during reward feedback and anticipation in healthy subjects. During similar reward feedback and anticipation tasks, patients with SZ demonstrated hypoactivation in VS, which was correlated with severity of negative symptoms (table 1). ${ }^{15}$ Together, these findings are consistent with SZ being associated with both increases in presynaptic dopamine causing psychotic symptoms and with hypoactivation of the striatum, that in conjunction with frontal lobe circuitry may contribute to cognitive and negative symptoms.

In SZ, there are significant reductions in whole-brain total grey matter overall consistently involving both cortical and hippocampal grey matter and accompanied by 0.3 -fold ventricular enlargement (table 1). ${ }^{20}$ Reduction of cortical grey matter may be progressive and lead to ventricular enlargement, and may occur at an accelerated rate in prodromal subjects who subsequently convert to psychosis. ${ }^{50}$ Hippocampal volume reduction has a larger effect size noted in male patients. ${ }^{22}$ Reduction is bilateral and stable throughout disease course (table 1). ${ }^{22}$ Furthermore, the left hippocampus has been found to be hypoactive during resting state, along with areas (eg, ventromedial prefrontal cortex) involved in the default mode network, a 


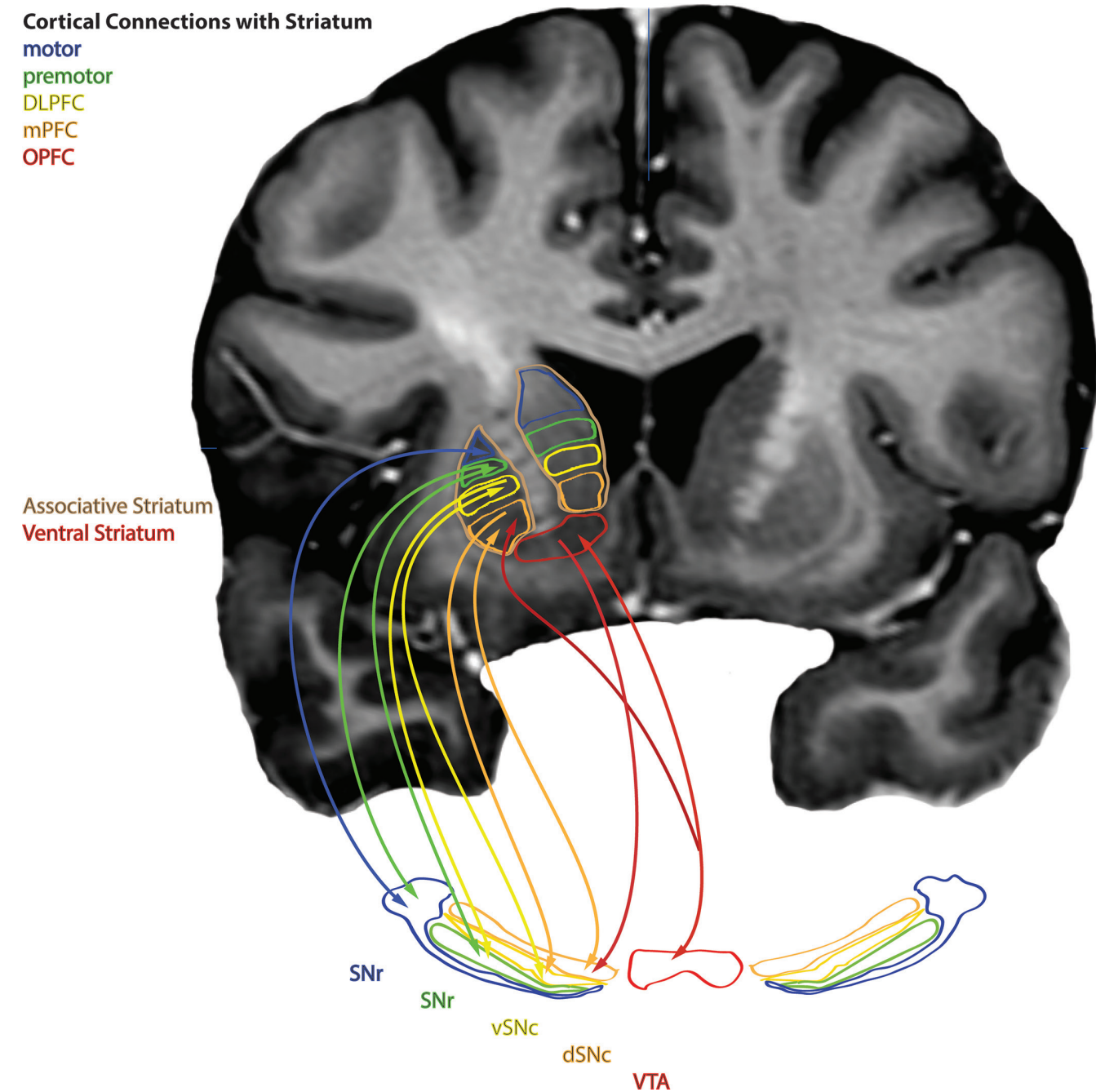

Figure 2 Striatonigrostrial ascending spiral of subcircuitry involved in striatal dopamine regulation. Closed reciprocal (CR) loop representing dopaminergic neurons projecting to distinct regions in the striatum and reciprocal inhibitory projections (double headed arrows) and disinhibitory feedforward regulation to adjacent substantia nigra (SN) regions (single headed arrows). DLPFC, dorsolateral prefrontal cortex; dSNc, dorsal tier SNc; mPFC, medial prefrontal cortex; OPFC, orbital prefrontal cortex; SNr, substantia nigra pars reticulata; vSNc, ventral tier SN pars compacta; VTA, ventral tegmental area.

network activated during rest or times of assessing self-perception (table 1). ${ }^{18}$ Also reported are reductions in deep white matter tracts including one that traverses temporal lobe with connectivity between frontal lobe, insula, hippocampus-amygdala and temporal and occipital lobes (table 1). ${ }^{26}$ Hypoactivation measured by blood-oxygen-level dependent (BOLD) fMRI may relate to recent findings of a hypermetabolic state in the hippocampus measured with cerebral blood volume (table 1). ${ }^{17}$ One mechanistic model (model 1) of SZ pathology based on NMDA antagonism inducing both positive and negative symptoms encompasses the temporal finding of a hypermetabolic state initiating in the cornu ammonis 1 region of the hippocampus preceding the hyperdopaminergic state in the striatum (tables 1 and 2; figures 1 and 3). ${ }^{17}$ Hypermetabolism may occur through the build-up of extracellular glutamate (GLU) that leads to hippocampal atrophy followed by increases in presynaptic dopamine in the striatum. Consistent with hippocampal drive, there is increased GLU and its metabolites in BG and in the hippocampus (table 1). ${ }^{14}$ Increased extracellular GLU without an essential cofactor may not translate to increased glutamatergic signalling. Blocking glutamatergic release within the hippocampus is a potential therapeutic target that has been difficult to achieve with pharmaceuticals, in part due to the ubiquitous nature of glutamatergic circuitry, and to the systemic nature of pharmaceutical treatment. DBS targeting the hippocampus or a hippocampal input structure, MSN, may counteract the functional consequences of the noted aberrances in the hippocampus that are thought to drive the psychotic state..$^{51-54}$ Targeting hippocampus or MSN may also treat negative and cognitive symptoms (figure 1, table 2). ${ }^{591016172527-42}$

\section{DBS mechanisms and biomarkers of SZ disease to inform DBS}

- DBS modulates synchrony and alters oscillatory activity within neural networks. ${ }^{8}$

- Intraoperative biomarkers are needed to facilitate identification of the deep brain structure being targeted.

- Biomarkers that predict an altered disease state and respond to DBS are needed to inform both intraoperative targeting and DBS programming. ${ }^{8}$

A consensus has not been reached about DBS therapeutic mechanisms, which are likely target and disease specific. ${ }^{55}$ DBS may provide benefit through different physiological mechanisms; for instance, DBS of the subthalamic nucleus in PD has 


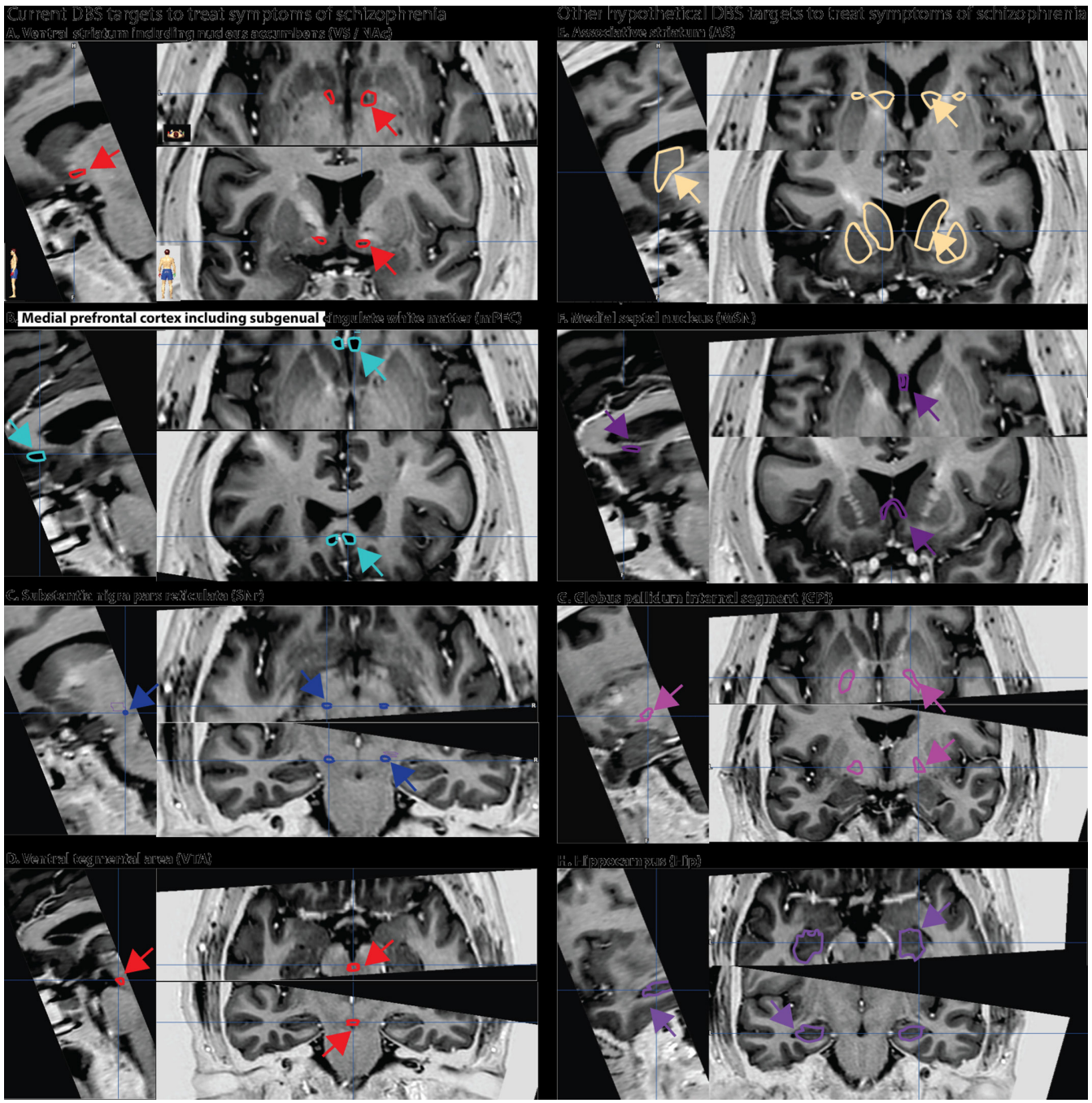

Figure 3 Targets for deep brain stimulation (DBS) to treat symptoms of schizophrenia (SZ) shown with sagittal, axial and coronal MRIs without contrast.

been shown to modulate aberrant firing bursts, beta band oscillations and beta band coupling/synchronisation locally and within efferent structures like globus pallidus internal (GPi). ${ }^{85}$ Similarly, for OCD, Figee et $a l^{56}$ identified that NAc DBS reduced low-frequency oscillations $(2-5 \mathrm{~Hz})$ elicited in the frontal cortex in response to OCD symptom-provoking images. ${ }^{56}$ In addition, fMRI brain imaging studies identified decreased NAc activity in the ventral striatal-orbitofrontal circuitry during reward anticipation relative to healthy controls that was normalised with DBS. ${ }^{57}$ Finally, effective DBS reduced resting state NAc hyperconnectivity to both lateral and medial prefrontal cortex (mPFC) that was correlated with reduction in OCD symptoms $(\mathrm{r}=0.72) .{ }^{56} \mathrm{In}$ a subsequent investigation, Figee et $a l^{9}$ showed that NAc DBS induced release of striatal dopamine that was correlated with a $45 \%$ decrease in OCD symptoms. ${ }^{9}$ An optimal response time occurs after months of DBS for OCD. This is consistent with inducing neuroplasticity and studies in rats found that DBS of the NAc/VS increased expression of the neuronal plasticity marker, phosphorylated extracellular signal-regulated kinase, in medial orbitofrontal cortex neurons which correlated with reduced fear expression. ${ }^{55} 5859$ Evidence supports DBS effects on local, afferent and efferent structures, with both stimulatory and inhibitory effects, modulating coherence and synchronicity, and occurring immediately via electrical modulation to months through inducing neuronal plasticity. ${ }^{955} 5660$
The NAc is a DBS target for both OCD and SZ. Similarly, $\mathrm{mPFC}$ is targeted in both major depressive disorder (MDD) and SZ. DBS of either NAc or mPFC targets has been shown in the maternal immune activation (MIA) rat model of SZ to prevent neuroinflammation marked by increased microglial aggregation in the hippocampus. ${ }^{61}$ Furthermore, DBS of mPFC prevented the development of increased ventricular volumes as well as additional SZ-related developmental abnormalities characteristic of MIA rats, including deficits in: (1) prepulse inhibition (PPI), a measure of sensory motor gating of acoustic startle; (2) disrupted latent inhibition; and (3) discrimination reversal, a measure of executive function. ${ }^{62}$ Effective DBS of mPFC for patients with MDD is associated with normalising increased $\mathrm{rCBF}$ in subgenual cingulate white matter (SGCWM) and changed activity at multiple sites within the limbic-cortical circuitry. ${ }^{63}$ Possibly relevant to DBS targeting $\mathrm{mPFC}$ to treat SZ, effective DBS targeting $\mathrm{mPFC}$ in MDD has been associated with theoretical activation of multiple intercepting white matter tracts, including one with connectivity to the striatum and another, the forceps minor, with connectivity to ventromedial frontal cortex. Intraoperative transient stimulation of the forceps minor induces changes in interoceptive and exteroceptive awareness. ${ }^{64-66}$ Intraoperative detection of these stimulation-induced behavioural changes is indicative of optimal DBS electrode placement within mPFC to treat MDD. 
For movement disorders, optimal DBS macroelectrode placement can be confirmed intraoperatively when stimulation directly alleviates symptoms of PD or ET without causing intolerable side effects. Before DBS macroelectrode placement, the region likely to provide maximal therapeutic benefit can be identified with microelectrode recordings that identify specific deep brain structures based on both characteristic single-unit activity firing patterns and by noting the physiological effects of stimulation (kinesthetic testing, induced half-smile). Identifying the stimulation-induced half-smile intraoperatively is thought to be necessary, but not sufficient for effective NAc targeting; $60 \%$ of patients with OCD treated with DBS respond with a $45.1 \%$ reduction of symptoms assessed by Yale Brown Obsessive-Compulsive Scale (YBOCS). ${ }^{64}{ }^{67}$ Additional DBS treatment-responsive neurophysiological biomarkers are being investigated in OCD including PPI. In the PPI paradigm, a weaker prepulse proceeding a reflexive startle-inducing pulse normally reduces the startle response measured by eye blink with electroculogram. In both OCD and SZ, the prepulse is less effective at gating the startle response. Pharmacological investigations show that PPI is regulated by dopamine, GLU, serotonin and acetylcholine. ${ }^{68} \mathrm{NAc}$ is part of the PPI circuitry and DBS of NAc, medial dorsal (MD) and mPFC targets relevant to SZ improved PPI in various rat SZ models. ${ }^{11} 306970$ Therefore, the effects of DBS targeting NAc on PPI were investigated in patients with OCD and DBS improved PPI. ${ }^{68}$ Overall, YBOCS scores decreased by $22 \%$ in the eight patients and higher symptom severity was negatively correlated with lower PPI $(-0.60) \cdot{ }^{68}$ Further investigations are warranted to determine if PPI can be used as a treatment-responsive biomarker. Parallel experiments should be performed during DBS clinical trials for SZ that target NAc to determine whether improving PPI is associated with effective DBS.

A similar sensory processing paradigm used to assess aberrant gating in SZ, the auditory-evoked P50 response to paired clicks, has been investigated as a DBS treatment-responsive biomarker for ventral hippocampus and NAc DBS in animal models of SZ. ${ }^{30}{ }^{71}$ Deficits in P50 gating are thought to reflect aberrant neuropathology related to cognitive deficits with some studies reporting significant findings related P50 gating to attention. ${ }^{72-74}$ While PPI and P50 gating share some circuitry, P50 gating has also been mapped to DLPFC in patients with SZ-making the P50 response a potentially useful intraoperative biomarker, if detectable with local field potential (LFP), for identifying circuitry within DBS targets (AS and substantia nigra pars reticulata $(\mathrm{SNr})$ ) connecting to DLPFC. ${ }^{75}$

Finally, aberrant neurophysiology related to SZ assessed with EEG is being sought to inform the development of novel therapeutic interventions including identifying changes in oscillatory frequencies such as increased resting state gamma oscillations. ${ }^{76}$ More work needs to be done to determine if increased resting state gamma oscillations: (1) can be consistently identified in SZ; (2) can be localised to deep brain structures within specific circuitry (measured by both LFP and EEG simultaneously to assess coherence and synchrony); (3) can be associated with specific symptoms; and (4) can be normalised in response to effective therapy. Similar efforts are being pursued in PD where the effects of DBS on reducing enhanced beta-band activity, measured with LFPs, are under investigation. ${ }^{8}$

Other DBS-related biomarkers relevant to treating SZ have been investigated. Dopaminergic neuron activity was normalised/ reduced in the VTA in response to DBS of the ventral hippocampus raising the possibility of monitoring neurophysiology at one site for responsive stimulation at another site..$^{32}$ In addition, development of treatment-responsive biomarkers may include
DBS macroelectrodes that can sample and quantitate local neurotransmitter levels such as dopamine in the striatum or with further development GLU in the hippocampus. ${ }^{77}$

\section{Phase I clinical DBS trials to treat SZ}

- NCT0237505 targets: (1) mPFC; and (2) NAc-62\% reduction in positive and 33\% improvement in negative symptoms (https://clinicaltrials.gov/ct2/show/NCT02377505).

- NCT02361554 targets SNr (https://clinicaltrials.gov/ct2/ show/NCT02361554).

- NCT01725334 targets: (1) NAc; and (2) VTA (withdrawn due to difficulty enrolling patients; https://clinicaltrials.gov/ ct2/show/NCT01725334).

There are two reports of DBS targeting NAc (VC/VS) in patients with SZ. ${ }^{28} 78$ In a patient with both OCD and residual SZ, symptoms of OCD and psychosocial functioning were $25 \%-58 \%$ improved with unilateral stimulation of NAc. However, the patient's predominant negative symptoms of SZ were not significantly changed by DBS. Importantly, DBS did not cause symptoms of psychosis. ${ }^{78}$

The response of the first patient with SZ treated with DBS targeting NAc in the clinical trial (NCT0237505) at Barcelona, Spain, was recently reported to show a $62 \%$ reduction in positive symptoms and 33\% improvement in negative symptoms after 4 weeks of unilateral left side stimulation. Akathisia occurred immediately during bilateral stimulation and after adjusting to unilateral stimulation, the patient experienced a relapse of negative symptoms, with her positive symptoms remaining improved over baseline. ${ }^{28}$ Treatment-resistant patients are randomised to either mPFC or NAc DBS targeting, with stimulation on until the patient is clinically stabilised. Then, responsive patients are crossed over to either a stimulation 'on' or a stimulation 'off' group for 3 months. The mPFC target includes the SGCWM, which has been targeted experimentally for treatment-resistant major depression (figure 3, table 2). ${ }^{59} 1016172527-42$ Therefore, targeting SGCWM may treat negative symptoms. In addition, this target includes the anterior midline node of the default network that normally deactivates during attention-demanding tasks. In SZ, there is a failure to deactivate during attention-demanding tasks. ${ }^{334}$ At the time of writing, this trial has recruited seven of a planned eight patients (four for each of the two implantation targets), of whom six have progressed to activation of stimulation (one patient suffered postoperative complications which ultimately required removal of the electrodes).

In the DBS clinical trial (NCT02361554) to treat positive and cognitive symptoms of SZ at Johns Hopkins University (JHU), $\mathrm{SNr}-\mathrm{a}$ major outflow nucleus of the BG-is targeted to modulate MD thalamus. ${ }^{36}$ Both MD and the lateral prefrontal cortex (including DLPFC) with strong reciprocal connections have reduced regional glucose metabolic rates during both spatial attention and verbal learning tasks in unmedicated SZ. ${ }^{40}$ Similarly, investigations using a mouse model that recapitulates the lowered MD activity identified in SZ, identified associations between low MD activity with both decreased beta-band thalamocortical synchrony measured with LFP and working memory impairment. ${ }^{37}$ The MD is also a proposed DBS target for treating anxiety and $\mathrm{SZ}$ cognitive symptoms and MD stimulation results in increased transcription of a genetic marker of neural plasticity, zif-268, in frontal cortex in rats. ${ }^{40} 79$ In addition, lesions of the MD have been associated with new-onset psychosis. ${ }^{38} 39$ Therefore, DBS targeting the subterritory of the $\mathrm{SNr}$ with afferent projections to the MD may modulate both the aberrant network activity of the BG and downstream circuitry (MD and lateral 
prefrontal cortex). ${ }^{8}$ The inhibitory projection from $\mathrm{SNr}$ to MD is a shared projection in both BG 'associative' and 'ventral' circuits. ${ }^{8}$ Normalising MD activity may provide improvement in both cognitive and positive symptoms. The JHU DBS Team based their assumption about MD on the evidence that the thalamus plays a central integrative role in structures that modulate motor and cognitive circuits like BG and cerebellum. ${ }^{4142}$

The closed DBS clinical trial (NCT01725334) to treat negative symptoms of SZ at University Health Network in Toronto, Canada, proposed two target areas: VS/NAc and VTA. Targeting VS/NAc may treat both positive and negative symptoms of SZ by balancing the dopaminergic tone in the striatum. Recently, a prospective study of anterior capsulotomy without a comparison group reported improvement in $74 \%$ of the 100 patients with SZ at a 2-year follow-up. ${ }^{5657}$ Consistent with other reports in the Chinese literature, improvement in aggressive behaviour, psychosis and negative symptoms were reported. For OCD, the effectiveness of both capsulotomy and DBS of VS/VC/NAc is similar and DBS of VS/NAc to treat SZ may indirectly validate the capsulotomy findings; the first person with SZ treated in the DBS clinical trial (NCT0237505) targeting VS/NAc did show improvement in both positive and negative symptoms. ${ }^{28} 303170$ Both VS/NAc and VTA are involved in the reward and motivation pathway that may relate to negative symptoms of SZ. Based on intracranial self-stimulation research used to map circuitry involved in reward in humans and rodents, VTA stimulation is pleasurable. ${ }^{80}$ VTA dopamine release into the striatum is modulated by NAc in conjunction with the hippocampus (figure 1). In a mechanistic model (model 3) of SZ, high dopamine levels in the striatum accompanied decreased dopamine levels in the prefrontal cortex from mesocortical VTA dopaminergic neurons. ${ }^{27}$ Stimulating VTA increases dopamine in the VS/NAc and increases activation of cortical structures such as DLPFC in swine, supporting the idea that negative symptoms of SZ may be treated by targeting VTA. ${ }^{77}$ Likewise, cognitive deficits caused by low dopamine levels in the cortex may be reduced.

DBS clinical trial \#NCT01725334 for the treatment of SZ was closed due to difficulties enrolling patients. One patient met the enrolment criteria and was interested in the clinical trial, but instead chose to participate in a different clinical trial. Similarly, DBS clinical trial \#NCT02361554 has not yet enrolled a patient, though several patients have been considered for enrolment. Using the Food and Drug Administration (FDA)-approved investigational device exemption (IDE) for JHU, additional sites (Columbia and University of Colorado) have been added to this trial as a strategy to increase enrolment. Multiple factors have contributed and may continue to contribute to difficulties with patient enrolment. The lack of both drive and sense of purpose associated with negative symptoms may hinder patient participation. Similarly, the nature of the delusional experience, itself, has prevented some patients from participating. Clinical trial \#NCT02361554 enrolled two patients who decided ultimately to withdraw from the study for the reason that their delusional experience could not be changed by DBS because it was 'real' to them. This is in contrast to patients with OCD and patients with major depression. Clinical trial \#NCT02361554 declined a patient referral from a forensic facility where the patient's psychiatrist raised the issue about equal rights of forensic versus non-forensic patient participation. It is possible that as awareness is raised in patients, family members and psychiatrists regarding the potential therapeutic benefits that DBS may provide, that study enrolment will accelerate. DBS clinical trial \#NCT0237505 has successfully enrolled seven patients. The DBS clinical trials to date have been funded through grants
(NCT0237505 and NCT01725334), and by seeking FDA, IDE along with Centers for Medicare and Medicaid Services approval for reimbursement (NCT02361554). ${ }^{48}$

\section{Ethics of DBS to treat SZ}

- Patients with severe symptoms despite treatment must have the capacity to consent for a DBS clinical trial in which risks can be estimated, but benefit is not known.

- Psychiatric populations should have access to the potential benefits of neurosurgical advances.

Vigilant evaluation of ethical concerns is paramount when considering the investigation of DBS for patients with SZ (SZ-DBS). The controversial history of psychosurgery may lead many to be wary of DBS. However, when we review the ethical principles in the Belmont Report, with respect to beneficence, respect for persons and justice, the picture is favourable. ${ }^{81}$ The FDA Humanitarian Device Exemption approval of DBS for OCD can also provide a model for the ethical delivery of DBS in psychiatric disorders.

The first principle, beneficence, requires an acceptable risk/ benefit ratio. A significant proportion of patients with SZ remain severely impaired and non-responsive to standard treatment. DBS may potentially help such patients. The risks of DBS must be weighed against these potential benefits. The risks include: procedure-related adverse effects such as symptomatic haemorrhage $(0.78 \%-1.1 \%)^{82}{ }^{83}$; infection $(1.7 \%-6.1 \%)^{82} 84$; device-related effects such as battery failure or lead fracture (requiring surgical replacement and additional risk); and stimulation-related effects. ${ }^{82}$ DBS for SZ, then, involves 'more than a minor increase over minimal risk' but also offers the prospect of direct medical benefit. ${ }^{85}$ As the risk/benefit ratio increases, there must be increased certainty about an individual's capacity to consent. ${ }^{86}$

The second principle, respect for persons, is embodied in informed consent. The two ethical considerations are the right for individuals to make autonomous decisions and the protection of those with diminished autonomy. There must be additional ethical justification when researching a vulnerable population such as patients with SZ. Patients with SZ, as a group, perform more poorly than controls on measures of capacity. For example, MacArthur Competence Assessment Tool for Clinical Research (MacCAT-CR SZ) patients score in an impaired range in $22.6 \%$ of the cases, ${ }^{87}$ and on the California Scale of Appreciation (CSA) the three raters found $7.7 \%, 10.3 \%$ and $12.8 \%$ incapable. $^{88}$ It should be noted that the subjects of the CSA study were all outpatients, while the subjects in the MacArthur study were inpatients. ${ }^{87} 88$ In the Carpenter et al's study, capacity varied widely, and SDs were large. ${ }^{89}$ Of patients with SZ who initially performed poorly, a week-long educational intervention resulted in no difference in the mean scores between the SZ group and the normal controls. This patient cohort was skewed towards those with treatment-resistant chronic SZ, likely similar to those who would be DBS candidates. Two additional studies demonstrate the effectiveness of improving comprehension using enhanced consent in patients with SZ. ${ }^{90}$ Based on these studies, two recommendations include: (1) the capacity to consent to DBS should be assessed by a psychiatrist with extensive experience in capacity evaluation, using a standardised measure of capacity such as the MacCAT-CR, the more clinically feasible MacCAT-Treatment ${ }^{87}$ or the CSA; and (2) patients who lack capacity upon presentation may have capacity restored with an educational intervention.

The third principle, justice, includes equity and fairness in healthcare, and new treatments or experimental procedures 
should be available to all people equally. Psychiatric populations, including patients with treatment-resistant, severe SZ should have access to the potential benefits of neurosurgical advances.

In 2002, the OCD-DBS Collaborative Group developed ethics recommendations for DBS in OCD, ${ }^{91}$ of relevance to SZ-DBS. These include: institutional review board (IRB) (or equivalent ethics committee) providing oversight; evaluating capacity and obtaining informed consent (processes monitored by a multidisciplinary committee); SZ-DBS candidates meeting defined criteria for severity, chronicity, disability and treatment resistance; excluding those without a capacity to consent; allowing freedom to withdraw from the research; intervention offered at a clinical research centre; assessment and treatment done by a multidisciplinary team which includes a neurosurgeon experienced in DBS and a psychiatrist experienced in the treatment of those with SZ; disclosure of investigator conflict of interest to patients and the IRB; SZ-DBS performed only for the benefit of the patient (to relieve distress and suffering); and SZ-DBS never performed for law enforcement or social/political purposes.

To aid in appropriate patient selection, severity, chronicity, disability and treatment refractoriness in SZ must be defined:

- Diagnosis

- Made via astandardised interview. ${ }^{6}$

- Severity

- Severe symptoms (cognitive,positive or negative)—rating of symptom levels of at least severe of one or more items on a validated scale such as the Brief Psychiatric Rating Scale (BPRS) or the Positive and Negative Syndrome Scale (PANSS) at baseline measurement.

- Chronicity

- Persistence of symptoms for at least 12 weeks despite adequate pharmacotherapy. ${ }^{6}$

- Disability

- Functional impairment as measured by a validated scale, clinical interview and history.

- Treatment refractoriness

- Adequate pharmacotherapy $=$ trials of at least two antipsychotic medications at doses greater than or equal to $600 \mathrm{mg}$ of chlorpromazine equivalents for at least 6 weeks each with at least $80 \%$ adherence and failure to respond to an adequate trial of clozapine (at least 3 months with a therapeutic plasma level). ${ }^{6}$

- Treatment-resistant patients with severe symptoms who are unable to tolerate clozapine at the recommended dose or duration may also be included in the clinical trial.

The NCT02361554 trial (SNr) defines severe as at least a score of 6 on two of the three BPRS positive symptom scales at three baseline visits prior to surgery. The NCT0237505 trial uses persistence of positive symptoms defined as (1) a score of 4 (mild) or more on at least two of the PANSS items: delusions, hallucinatory behaviour, suspiciousness and unusual thought content; or as (2) requiring a score of 6 (severe) or more on at least one of the above PANSS items. Several patients with SZ have provided informed consent and were safely treated with DBS. ${ }^{10} 2878$

The use of neuromodulation for the treatment of SZ is a controversial subject, and underscores the need for a cautious, thoughtful approach to trial design, so that this vulnerable patient population-that may benefit from SZ-DBS-is protected. As with any clinical trial, the ethical principles of the Belmont Report-including beneficence, respect for persons and justice-provide the critical framework in which such efforts must be tackled. The successful experience with DBS for the treatment of OCD provides a foundation for the ethical delivery of DBS in a population of patients with psychiatric illnesses, and thus has important implications for the treatment of SZ. Finally, appropriate subject selection is always crucial, and subjects enrolled in an SZ-DBS clinical trial should meet criteria for 'ultra-treatment resistance', and continue to experience severe symptoms and functional impairment for at least 12 weeks prior to DBS treatment, as measured by standardised psychiatric rating scales. Thorough and responsible consideration of these factors will contribute to ensuring the ethical investigation of SZ-DBS.

\section{CONCLUSIONS}

In summary, evidence is consistent with SZ being a circuit disorder similar to other disorders treated with DBS. Several lines of evidence together support modulating the striatum with DBS for the treatment of SZ, including: (1) the specificity of antipsychotics for dopamine $\mathrm{D}_{2}$-like receptors that are concentrated in striatum; (2) the occupancy of $\mathrm{D}_{2}$-like receptors in the striatum is associated with effective treatment; (3) increased levels of presynaptic dopamine in the striatum of patients with SZ (may be lower in treatment-resistant patients); (4) genetic findings of association between the DRD2 gene and SZ. Effectively modulating the striatum may be achieved by targeting input structures such as VTA, hippocampus or MSN, targeting the associative and/or VS (including NAc) directly, or targeting $\mathrm{BG}$ output structures such as $\mathrm{SNr}$ and/or GPi. The targets in ongoing DBS clinical trials include SNr, NAc and mPFC. There are several potential advantages to DBS treatment that may compliment antipsychotic treatment by providing a unique therapeutic mechanism that may benefit otherwise treatment-resistant patients, reduce relapse rates, reduce intensity of residual psychosis, improve cognitive impairment and reduce negative symptoms. The potential benefits of DBS neurosurgical intervention warrant clinical trials in treatment-resistant patients or patients experiencing life-threatening antipsychotic side effects who are capable of providing informed consent.

\section{Author affiliations}

${ }^{1}$ Department of Neurosurgery, University of Colorado at Denver Anschutz Medical Campus, Aurora, Colorado, USA

${ }^{2}$ Department of Psychiatry, University of Colorado Anschutz Medical Center, Aurora, Colorado, USA

${ }^{3}$ Department of Psychiatry, School of Medicine, Johns Hopkins University, Baltimore, Maryland, USA

${ }^{4}$ University of Southern California Law School, Los Angeles, California, USA

${ }^{5}$ Psychiatric Department, Hospital de la Santa Creu i Sant Pau, Institut d'Investigació Biomèdica Sant Pau (IIB-Sant Pau), Universitat Autònoma de Barcelona, Barcelona,

Catalonia, Spain

${ }^{6}$ Centro de Investigación Biomédica en Red de Salud Mental (CIBERSAM), Barcelona, Spain

${ }^{7}$ Department of Neurosurgery, Johns Hopkins Hospital, Baltimore, Maryland, USA

${ }^{8}$ Centro de Investigación Biomédica en Red de Salud Mental (CIBERSAM), FIDMAG Germanes Hospitalàries Research Foundation, Barcelona, Spain

${ }^{9}$ Centre for Addiction and Mental Health Collaborative Program in Neuroscience, University of Toronto, Toronto, Ontario, Canada

${ }^{10}$ Division of Neurosurgery, Sunnybrook Health Science Centre, University of Toronto, Toronto, Ontario, Canada

${ }^{11}$ Department of Neurology, University of Colorado Anschutz Medical Campus, Aurora, CO, USA

Acknowledgements The authors would like to acknowledge the contributions of Peter McKenna, MD, PhD, for information pertaining to clinical trial NCT0237505, and Julia Liedtke for helping with the video.

Contributors JMG: substantial contributions to the conception and design of the work, and the acquisition, analysis and interpretation of data; drafting the work (except the ethics section), revising the entire manuscript critically for important intellectual content; final approval of the version published; agreed to be accountable for all aspects of the work in ensuring that questions related to 
the accuracy or integrity of any part of the work are appropriately investigated and resolved. RD: final approval of the version published; drafting the ethics section and revising the entire manuscript critically for important intellectual content. NGC: final approval of the version published; drafting the Hopkins clinical trial section and revising the entire manuscript critically for important intellectual content. ERS, JD: final approval of the version published; contributed to the ethics section draft and critical revision; contributed to the video. ICC, EPC: final approval of the version published; drafting the Barcelona Spain clinical trial section and revising it critically for important intellectual content. WSA, JAT: final approval of the version published; revising the entire manuscript for important intellectual content; reviewed accuracy of figure 3 DBS targets. AO, AS: final approval of the version published; revising the entire manuscript for important intellectual content. ZJD, NL: final approval of the version published; revising the University of Toronto clinical trial for important intellectual content. AA: final approval of the version published; critically revised the entire manuscript for important intellectual content; agreed to be accountable for all aspects of the work in ensuring that questions related to the accuracy or integrity of any part of the work are appropriately investigated and resolved.

Funding Funding for this work was provided through an Independent Investigator NARSAD Grant through the Brain and Behavior Research Foundation (Grant ID 23295, JMG) and NIH grant 1RC1MH088735.

\section{Competing interests None declared.}

Provenance and peer review Commissioned; externally peer reviewed.

(c) Article author(s) (or their employer(s) unless otherwise stated in the text of the article) 2018. All rights reserved. No commercial use is permitted unless otherwise expressly granted.

\section{REFERENCES}

1 Harrison G, Hopper K, Craig T, et al. Recovery from psychotic illness: a 15- and 25-year international follow-up study. Br J Psychiatry 2001;178:506-17.

2 Subotnik KL, Casaus LR, Ventura J, et al. Long-acting injectable risperidone for relapse prevention and control of breakthrough symptoms after a recent first episode of schizophrenia. A randomized clinical trial. JAMA Psychiatry 2015;72:822-9.

3 Citrome L, Eramo A, Francois C, et al. Lack of tolerable treatment options for patients with schizophrenia. Neuropsychiatr Dis Treat 2015;11:3095-104.

4 Andreasen NC, Liu D, Ziebell S, et al. Relapse duration, treatment intensity, and brain tissue loss in schizophrenia: a prospective longitudinal MRI study. Am J Psychiatry 2013;170:609-15.

5 Sarkar S, Hillner K, Velligan DI. Conceptualization and treatment of negative symptoms in schizophrenia. World J Psychiatry 2015;5:352-61.

6 Howes OD, McCutcheon R, Agid O, et al. Treatment-resistant schizophrenia: Treatment Response and Resistance in Psychosis (TRRIP) working group consensus guidelines on diagnosis and terminology. Am J Psychiatry 2017;174:216-29.

7 Robinson D, Woerner MG, Alvir JM, et al. Predictors of relapse following response from a first episode of schizophrenia or schizoaffective disorder. Arch Gen Psychiatry 1999;56:241-7.

8 de Hemptinne C, Swann NC, Ostrem JL, et al. Therapeutic deep brain stimulation reduces cortical phase-amplitude coupling in Parkinson's disease. Nat Neurosci 2015;18:779-86.

9 Figee $\mathrm{M}$, de Koning $\mathrm{P}$, Klaassen $\mathrm{S}$, et al. Deep brain stimulation induces striatal dopamine release in obsessive-compulsive disorder. Biol Psychiatry 2014:75:647-52.

10 Chang EF, Schrock LE, Starr PA, et al. Long-term benefit sustained after bilateral pallidal deep brain stimulation in patients with refractory tardive dystonia. Stereotact Funct Neurosurg 2010;88:304-10.

11 Schwabe K, Krauss JK. What rodent models of deep brain stimulation can teach us about the neural circuit regulation of prepulse inhibition in neuropsychiatric disorders. Schizophr Res 2017.

12 Eisenberg DP, Yankowitz L, lanni AM, et al. Presynaptic dopamine synthesis capacity in schizophrenia and striatal blood flow change during antipsychotic treatment and medication-free conditions. Neuropsychopharmacology 2017;42:2232-41.

13 Bernard JA, Russell CE, Newberry RE, et al. Patients with schizophrenia show aberrant patterns of basal ganglia activation: Evidence from ALE meta-analysis. Neuroimage Clin 2017;14:450-63.

14 Merritt K, Egerton A, Kempton MJ, et al. Nature of glutamate alterations in schizophrenia: a meta-analysis of proton magnetic resonance spectroscopy studies. JAMA Psychiatry 2016;73:665-74.

15 Radua J, Schmidt A, Borgwardt S, et al. Ventral striatal activation during reward processing in psychosis: a neurofunctional meta-analysis. JAMA Psychiatry 2015;72:1243-51.

16 Kambeitz J, Abi-Dargham A, Kapur S, et al. Alterations in cortical and extrastriatal subcortical dopamine function in schizophrenia: systematic review and meta-analysis of imaging studies. Br J Psychiatry 2014;204:420-9.

17 Schobel SA, Chaudhury NH, Khan UA, et al. Imaging patients with psychosis and a mouse model establishes a spreading pattern of hippocampal dysfunction and implicates glutamate as a driver. Neuron 2013;78:81-93.
18 Kühn S, Gallinat J. Resting-state brain activity in schizophrenia and major depression: a quantitative meta-analysis. Schizophr Bull 2013;39:358-65.

19 Yilmaz Z, Zai CC, Hwang R, et al. Antipsychotics, dopamine D, receptor occupancy and clinical improvement in schizophrenia: a meta-analysis. Schizophr Res 2012;140:214-20.

20 Sayo A, Jennings RG, Van Horn JD. Study factors influencing ventricular enlargement in schizophrenia: a 20 year follow-up meta-analysis. Neuroimage 2012;59:154-67.

21 Howes OD, Kambeitz J, Kim E, et al. The nature of dopamine dysfunction in schizophrenia and what this means for treatment. Arch Gen Psychiatry 2012;69:776-86.

22 Adriano F, Caltagirone C, Spalletta G. Hippocampal volume reduction in firstepisode and chronic schizophrenia: a review and meta-analysis. Neuroscientist 2012:18:180-200.

23 Kegeles LS, Abi-Dargham A, Frankle WG, et al. Increased synaptic dopamine function in associative regions of the striatum in schizophrenia. Arch Gen Psychiatry 2010;67:231-9.

24 Minzenberg MJ, Laird AR, Thelen S, et al. Meta-analysis of 41 functional neuroimaging studies of executive function in schizophrenia. Arch Gen Psychiatry 2009;66:811-22.

25 Lahti AC, Weiler MA, Holcomb HH, et al. Modulation of limbic circuitry predicts treatment response to antipsychotic medication: a functional imaging study in schizophrenia. Neuropsychopharmacology 2009;34:2675-90.

26 Ellison-Wright I, Bullmore E. Meta-analysis of diffusion tensor imaging studies in schizophrenia. Schizophr Res 2009;108:3-10.

27 Urs NM, Peterson SM, Caron MG. New concepts in dopamine D2 receptor biased signaling and implications for schizophrenia therapy. Biol Psychiatry 2017;81:78-85.

28 Corripio I, Sarró S, McKenna PJ, et al. Clinical improvement in a treatment-resistant patient with schizophrenia treated with deep brain stimulation. Biol Psychiatry 2016;80:e69-e70.

29 Sun B, Liu W. Reply to the letter by lévêque et al. entitled 'Psychosurgery for schizophrenia'. Stereotact Funct Neurosurg 2014;92:413.

$30 \mathrm{Ma}$ J, Leung LS. Deep brain stimulation of the medial septum or nucleus accumbens alleviates psychosis-relevant behavior in ketamine-treated rats. Behav Brain Res 2014:266:174-82.

31 Liu W, Hao Q, Zhan S, et al. Long-term follow-up of mri-guided bilateral anterior capsulotomy in patients with refractory schizophrenia. Stereotact Funct Neurosurg 2014;92:145-52

32 Perez SM, Shah A, Asher A, et al. Hippocampal deep brain stimulation reverses physiological and behavioural deficits in a rodent model of schizophrenia. Int $J$ Neuropsychopharmacol 2013;16:1331-9.

33 Whitfield-Gabrieli S, Thermenos HW, Milanovic S, et al. Hyperactivity and hyperconnectivity of the default network in schizophrenia and in firstdegree relatives of persons with schizophrenia. Proc Natl Acad Sci U SA 2009;106:1279-84.

34 Pomarol-Clotet E, Salvador R, Sarró S, et al. Failure to deactivate in the prefrontal cortex in schizophrenia: dysfunction of the default mode network? Psychol Med 2008;38:1185-93.

35 Haber SN, Fudge JL, McFarland NR. Striatonigrostriatal pathways in primates form an ascending spiral from the shell to the dorsolateral striatum. J Neurosci 2000;20:2369-82.

36 llinsky IA, Jouandet ML, Goldman-Rakic PS. Organization of the nigrothalamocortical system in the rhesus monkey. J Comp Neurol 1985;236:315-30.

37 Parnaudeau S, O'Neill PK, Bolkan SS, et al. Inhibition of mediodorsal thalamus disrupts thalamofrontal connectivity and cognition. Neuron 2013;77:1151-62.

38 Santos S, Alberti O, Corbalán T, et al. [Stroke-psychosis. Description of two cases]. Actas Esp Psiquiatr 2009;37:240-2.

39 Yoshida Y, Abe K, Yoshizawa K. [A case of left dorsomedial thalamic infarction with unilateral schizophrenia-like auditory hallucinations]. Seishin Shinkeigaku Zasshi 2006; 108:31-41

40 Lehrer DS, Christian BT, Mantil J, et al. Thalamic and prefrontal FDG uptake in never medicated patients with schizophrenia. Am J Psychiatry 2005;162:931-8.

41 Graybiel AM. The basal ganglia and cognitive pattern generators. Schizophr Bull 1997;23:459-69.

42 Schmahmann JD. An emerging concept. The cerebellar contribution to higher function. Arch Neurol 1991:48:1178-87.

43 Schizophrenia Working Group of the Psychiatric Genomics Consortium. Biological insights from 108 schizophrenia-associated genetic loci. Nature 2014;511:421-7.

44 Seeman P, Chau-Wong M, Tedesco J, et al. Brain receptors for antipsychotic drugs and dopamine: direct binding assays. Proc Natl Acad Sci U S A 1975;72:4376-80.

45 Masri B, Salahpour A, Didriksen M, et al. Antagonism of dopamine D2 receptor/betaarrestin 2 interaction is a common property of clinically effective antipsychotics. Proc Natl Acad Sci U SA 2008;105:13656-61.

46 Roberts RC, Roche JK, Conley RR, et al. Dopaminergic synapses in the caudate of subjects with schizophrenia: relationship to treatment response. Synapse 2009:63:520-30.

47 Demjaha A, Murray RM, McGuire PK, et al. Dopamine synthesis capacity in patients with treatment-resistant schizophrenia. Am J Psychiatry 2012;169:1203-10.

48 Weinstein JJ, Chohan MO, Slifstein M, et al. Pathway-specific dopamine abnormalities in schizophrenia. Biol Psychiatry 2017;81:31-42. 
49 Martin DM, McClintock SM, Forster J, et al. Does therapeutic repetitive transcranial magnetic stimulation cause cognitive enhancing effects in patients with neuropsychiatric conditions? A systematic review and meta-analysis of randomised controlled trials. Neuropsychol Rev 2016;26:295-309.

50 Chung Y, Haut KM, He G, et al. Ventricular enlargement and progressive reduction of cortical gray matter are linked in prodromal youth who develop psychosis. Schizophr Res 2017:30100-7.

51 Mikell CB, Sinha S, Sheth SA. Neurosurgery for schizophrenia: an update on pathophysiology and a novel therapeutic target. J Neurosurg 2016;124:917-28.

52 Salgado-López L, Pomarol-Clotet E, Roldán A, et al. Letter to the Editor: deep brain stimulation for schizophrenia. J Neurosurg 2016;125:229-30.

53 Kuhn J, Bodatsch M, Sturm V, et al. [Deep brain stimulation in schizophrenia]. Fortschr Neurol Psychiatr 2011;79:632-41.

54 Bakay RA. Deep brain stimulation for schizophrenia. Stereotact Funct Neurosurg 2009;87:266

55 Ashkan K, Rogers P, Bergman H, et al. Insights into the mechanisms of deep brain stimulation. Nat Rev Neurol 2017;13:548-54.

56 Figee M, Luigjes J, Smolders R, et al. Deep brain stimulation restores frontostriatal network activity in obsessive-compulsive disorder. Nat Neurosci 2013;16:386-7.

57 Figee M, Vink M, de Geus F, et al. Dysfunctional reward circuitry in obsessivecompulsive disorder. Biol Psychiatry 2011;69:867-74.

58 Rodriguez-Romaguera J, Do Monte FH, Quirk GJ. Deep brain stimulation of the ventral striatum enhances extinction of conditioned fear. Proc Natl Acad Sci U SA 2012;109:8764-9.

59 Rodriguez-Romaguera J, Do-Monte FH, Tanimura Y, et al. Enhancement of fear extinction with deep brain stimulation: evidence for medial orbitofrontal involvement. Neuropsychopharmacology 2015;40:1726-33.

60 Rochester L, Chastin SF, Lord S, et al. Understanding the impact of deep brain stimulation on ambulatory activity in advanced Parkinson's disease. J Neurol 2012;259:1081-6.

61 Hadar R, Dong L, Del-Valle-Anton L, et al. Deep brain stimulation during early adolescence prevents microglial alterations in a model of maternal immune activation. Brain Behav Immun 2017:63:71-80.

62 Hadar R, Bikovski L, Soto-Montenegro ML, et al. Early neuromodulation prevents the development of brain and behavioral abnormalities in a rodent model of schizophrenia. Mol Psychiatry 2017 [Epub ahead of print].

63 Mayberg HS, Lozano AM, Voon V, et al. Deep brain stimulation for treatment-resistant depression. Neuron 2005;45:651-60.

64 Choi KS, Riva-Posse P, Gross RE, et al. Mapping the "depression switch" during intraoperative testing of subcallosal cingulate deep brain stimulation. JAMA Neurol 2015:72:1252-60

65 Riva-Posse P, Choi KS, Holtzheimer PE, et al. A connectomic approach for subcallosal cingulate deep brain stimulation surgery: prospective targeting in treatment-resistant depression. Mol Psychiatry 2017.

66 Riva-Posse P, Choi KS, Holtzheimer PE, et al. Defining critical white matter pathways mediating successful subcallosal cingulate deep brain stimulation for treatmentresistant depression. Biol Psychiatry 2014;76:963-9.

67 Haq IU, Foote KD, Goodman WG, et al. Smile and laughter induction and intraoperative predictors of response to deep brain stimulation for obsessivecompulsive disorder. Neuroimage 2011;54(Suppl 1):S247-S255.

$68 \mathrm{Kohl}$ S, Gruendler TO, Huys D, et al. Effects of deep brain stimulation on prepulse inhibition in obsessive-compulsive disorder. Trans/ Psychiatry 2015;5:e675

69 Klein J, Hadar R, Götz T, et al. Mapping brain regions in which deep brain stimulation affects schizophrenia-like behavior in two rat models of schizophrenia. Brain Stimul 2013:6:490-9.
70 Bikovsky L, Hadar R, Soto-Montenegro ML, et al. Deep brain stimulation improves behavior and modulates neural circuits in a rodent model of schizophrenia. Exp Neurol 2016;283:142-50

71 Ewing SG, Grace AA. Deep brain stimulation of the ventral hippocampus restores deficits in processing of auditory evoked potentials in a rodent developmental disruption model of schizophrenia. Schizophr Res 2013;143:377-83.

72 Olincy A, Harris JG, Johnson LL, et al. Proof-of-concept trial of an alpha7 nicotinic agonist in schizophrenia. Arch Gen Psychiatry 2006;63:630-8.

73 Cullum CM, Harris JG, Waldo MC, et al. Neurophysiological and neuropsychological evidence for attentional dysfunction in schizophrenia. Schizophr Res 1993;10:131-41.

74 Yee CM, Nuechterlein KH, Morris SE, et al. P50 suppression in recent-onset schizophrenia: clinical correlates and risperidone effects. J Abnorm Psychol 1998;107:691-8.

75 Tregellas JR, Davalos DB, Rojas DC, et al. Increased hemodynamic response in the hippocampus, thalamus and prefrontal cortex during abnormal sensory gating in schizophrenia. Schizophr Res 2007;92:262-72

76 Featherstone RE, McMullen MF, Ward KR, et al. EEG biomarkers of target engagement therapeutic effect, and disease process. Ann N Y Acad Sci 2015;1344:12-26.

77 Settell ML, Testini P, Cho S, et al. Functional circuitry effect of ventral tegmental area deep brain stimulation: imaging and neurochemical evidence of mesocortical and mesolimbic pathway modulation. Front Neurosci 2017;11:104.

78 Plewnia C, Schober F, Rilk A, et al. Sustained improvement of obsessive-compulsive disorder by deep brain stimulation in a woman with residual schizophrenia. Int J Neuropsychopharmacol 2008;11:1181-3.

79 Maarouf M, Neudorfer C, El Majdoub F, et al. Deep brain stimulation of medial dorsal and ventral anterior nucleus of the thalamus in OCD: a retrospective case series. PLOS One 2016;11:e0160750.

80 Wise RA. Roles for nigrostriatal--not just mesocorticolimbic--dopamine in reward and addiction. Trends Neurosci 2009;32:517-24.

81 Department of Health E, and Welfare. The belmont report: ethical principles and guidelines for the protection of human subjects of research. Federal register. Washington, DC: DHEW Publication OS, 1978.

82 Fenoy AJ, Simpson RK. Risks of common complications in deep brain stimulation surgery: management and avoidance. J Neurosurg 2014;120:132-9.

83 Patel DM, Walker HC, Brooks R, et al. Adverse events associated with deep brain stimulation for movement disorders: analysis of 510 consecutive cases. Neurosurgery 2015;11(Suppl 2):190-9.

84 Voges J, Waerzeggers Y, Maarouf M, et al. Deep-brain stimulation: long-term analysis of complications caused by hardware and surgery--experiences from a single centre. J Neurol Neurosurg Psychiatry 2006;77:868-72.

85 Oldham JM, Haimowitz S, Delano SJ. Protection of persons with mental disorders from research risk: a response to the report of the National Bioethics Advisory Commission. Arch Gen Psychiatry 1999;56:688-93.

86 Buchanan A. Mental capacity, legal competence and consent to treatment. J R Soc Med 2004;97:415-20.

87 Grisso T, Appelbaum PS, Hill-Fotouhi C. The MacCAT-T: a clinical tool to assess patients' capacities to make treatment decisions. Psychiatr Serv 1997;48:1415-9.

88 Saks ER, Dunn LB, Marshall BJ, et al. The california scale of appreciation: a new instrument to measure the appreciation component of capacity to consent to research. Am J Geriatr Psychiatry 2002:10:166-74.

89 Carpenter WT, Gold JM, Lahti AC, et al. Decisional capacity for informed consent in schizophrenia research. Arch Gen Psychiatry 2000;57:533-8.

90 Dunn LB, Candilis PJ, Roberts LW. Emerging empirical evidence on the ethics of schizophrenia research. Schizophr Bull 2006;32:47-68.

91 Nuttin B, Wu H, Mayberg H, et al. Consensus on guidelines for stereotactic neurosurgery for psychiatric disorders. J Neurol Neurosurg Psychiatry 2014;85:1003-8. 